\title{
Selection for Divergent Reproductive Investment Affects Neuron Size and Foliation in the Cerebellum
}

\author{
Ryaan EL-Andari $^{\mathrm{a}}$ Felipe Cunha $^{\mathrm{a}}$ Barbara Tschirren ${ }^{\mathrm{b}}$ Andrew N. Iwaniuk ${ }^{\mathrm{a}}$ \\ ${ }^{a}$ Department of Neuroscience, University of Lethbridge, Lethbridge, AB, Canada; ${ }^{b}$ Centre for Ecology and \\ Conservation, University of Exeter, Penryn, UK
}

\section{Keywords}

Allometry $\cdot$ Birds $\cdot$ Cerebellum $\cdot$ Purkinje cell

\begin{abstract}
The cerebellum has a highly conserved internal circuitry, but varies greatly in size and morphology within and across species. Despite this variation, the underlying volumetric changes among the layers of the cerebellar cortex or their association with Purkinje cell numbers and sizes is poorly understood. Here, we examine intraspecific scaling relationships and variation in the quantitative neuroanatomy of the cerebellum in Japanese quail (Coturnix japonica) selected for high or low reproductive investment. As predicted by the circuitry of the cerebellum, the volumes of the constituent layers of the cerebellar cortex were strongly and positively correlated with one another and with total cerebellar volume. The number of Purkinje cells also significantly and positively co-varied with total cerebellar volume and the molecular layer, but not the granule cell layer or white matter volumes. Purkinje cell size and cerebellar foliation did not significantly covary with any cerebellar measures, but differed significantly between the selection lines. Males and females from the high-investment lines had smaller Purkinje
\end{abstract}

cells than males and females from the low-investment lines and males from the high-investment lines had less folded cerebella than quail from the low-investment lines. These results suggest that within species, the layers of the cerebellum increase in a coordinated fashion, but Purkinje cell size and cerebellar foliation do not increase proportionally with overall cerebellum size. In contrast, selection for differential reproductive investment affects Purkinje cell size and cerebellar foliation, but not other quantitative measures of cerebellar anatomy.

(c) 2020 S. Karger AG, Basel

\section{Introduction}

The cerebellum has a highly conserved internal circuitry, but it can vary tremendously in size and shape [Yopak et al., 2017]. This diversity in cerebellar size and shape is evident when comparing different vertebrate species, classes and orders, and is thought to underlie variation in motor control and sensorimotor integration across taxa [Larsell, 1967, 1970; Iwaniuk et al., 2006, 2007; Yopak et al., 2007; Lisney et al., 2008; Smaers et al., 2018]. One of the underlying mechanisms responsible for differ-

karger@karger.com www.karger.com/bbe

(c) 2020 S. Karger AG, Basel

Karger"
Dr. Andrew Iwaniuk

Department of Neuroscience

University of Lethbridge

Lethbridge, AB T1K3M4 (Canada)

andrew.iwaniuk@uleth.ca 
ences in relative cerebellar size across species is the number of neurons [Herculano-Houzel et al., 2015; Olkowicz et al., 2016]. That is, species with a larger, more folded cerebella have more neurons than species with smaller, less folded cerebella. Ultimately, this interspecific variation is often thought to be mediated by different lifestyles or ecological niches and differential selection pressures on motor control and/or sensorimotor integration [Jerison, 1973]. Neuroanatomical variation in the cerebellum is also associated with species differences in cognition and learning [Iwaniuk et al., 2009; Hall et al., 2013; Smaers et al., 2018], further supporting a link between anatomy and function in the cerebellum.

Cerebellar size and shape not only vary across species, but also within species [e.g., humans: Berquin et al., 1998; Fan et al., 2010; Bernard et al., 2015; non-human animals: Airey et al., 2002; Kihslinger and Nevitt, 2006; Cnotka et al., 2007]. Yet the underlying neuroanatomical changes responsible for intraspecific cerebellar variation have remained largely unstudied. In mutant strains of lab mice (Mus musculus), such as lurcher, woozy, and Purkinje cell deterioration $(p c d)$, a reduction in cerebellum size and foliation is often due to neuron loss [Vogel et al., 1989; Wang and Morgan, 2007; Hayashi et al., 2017]. However, all 3 of these strains, and others that experience Purkinje cell loss, are characterized by ataxic gaits and significantly impaired motor performance on a variety of tasks [Lalonde and Strazielle, 2001; Hayashi et al., 2017], so they are unlikely to represent natural variation in animal populations. Further, the relationship between cerebellar foliation and motor performance across mouse strains is currently unclear [Le Roy-Duflos, 2001], and data on cerebellar neuron numbers or sizes within and across mouse strains is wanting. The only study of intraspecific variation in cerebellum size that has examined neuron numbers focused on a single mouse strain (Swiss) and found that the number of neurons, excluding Purkinje cells, was weakly correlated with cerebellar mass [Herculano-Houzel et al., 2015]. This suggests that neuron numbers are not the sole determinant of intraspecific variation in cerebellum size [Herculano-Houzel et al., 2015], but data on the volumes of the different cerebellar layers and variation in Purkinje cell sizes or numbers is lacking. Thus, it is unclear how neuron numbers, neuron sizes and other measurements relate to intraspecific variation in cerebellar size and shape.

A recent artificial selection experiment in Japanese quail (Coturnix japonica) offers a novel means of determining what underlying cellular changes are responsible for intraspecific variation in cerebellum size. In this ex- periment, high and low maternal investment lines of Japanese quail were developed based on egg size [Pick et al., 2016a]. The female quail selected for high maternal investment had significantly smaller cerebella, in relative and absolute terms, than females from the low maternal investment line [Ebneter et al., 2016]. As with any brain region [Striedter, 2005], there are several potential changes that could be responsible for these strain differences in cerebellar size. The entire cerebellum could become smaller in a concerted fashion such that all of the cellular layers of the cerebellum decreased in size proportionally to one another. Alternatively, the size difference could arise primarily from a change in a specific layer or neuronal population within the cerebellum. For example, Purkinje cell loss is one of the mechanisms that contributes to decreases in cerebellar size and foliation in mutant mice [Vogel et al., 1989; Wang and Morgan, 2007; Hayashi et al., 2017]. Changes in Purkinje cell sizes or numbers could also contribute to cerebellar size in quail without affecting the sizes of the molecular or granule cell layers. Finally, cerebellum size and foliation are correlated with one another in birds [Iwaniuk et al., 2006] such that quail with smaller cerebella are likely to have a less folded cerebellar cortex. Here, we quantified the cerebellar anatomy of Japanese quail from the maternal investment artificial selection lines [Ebneter et al., 2016; Pick et al., 2016a] to determine what specific neuroanatomical effects have arisen from divergent selection on reproductive investment and explore intraspecific allometry of cell layers and Purkinje cell numbers and sizes.

\section{Materials and Methods}

Selection Lines for Divergent Reproductive Investment

Japanese quail were selected for high ( $\mathrm{H}$-line, 2 replicates) and low (L-line, 2 replicates) female reproductive investment using relative egg mass (i.e., egg mass corrected for female body mass and size) as the selection criterion [see Pick et al., 2016a for details]. After 5 generations of directional selection, the replicated $\mathrm{H}$ - and L-lines differed in egg mass by one standard deviation (mean \pm 1SD: $\mathrm{H}: 12.5 \pm 1.3$, L: $\left.11.3 \pm 0.9, F_{1,52}=13.100=p<0.001\right)$. H- and L-lines did not, however, differ in number of eggs laid, indicating that there was no correlated response between egg mass and numbers of eggs laid [Pick et al., 2016a]. In addition to differences in egg mass, the $\mathrm{H}$-line females have larger reproductive organs than L-line females [Pick et al., 2016b] and H-line quail tend to be larger [Pick et al., 2016b, c] with higher offspring survivorship than L-line quail [Pick et al., 2016c]. Further, H-line males experience higher reproductive success than L-males, which is associated with higher testis asymmetry in $\mathrm{H}$-line males [Pick et al., 2017].

For this study, males (H: $n=11, \mathrm{~L}: n=11)$ and females (H: $n=$ 13, L: $n=8$ ) from the fifth generation of the selection experiment were euthanized (gas mixture: $31 \% \mathrm{CO}_{2}, 2 \% \mathrm{O}_{2}$ and $67 \% \mathrm{Ar}$ ), 
Fig. 1. a A photomicrograph through one of the cerebellar folia showing the celldense granule cell layer ( $g c l)$ and cell poor molecular layer ( $\mathrm{ml}$ ). The intervening Purkinje cell layer is comprised on large, teardrop-shaped cell bodies, one of which is indicated by the arrow $(\mathrm{Pc})$. Scale bar $=50$ $\mu \mathrm{m}$. b A midsagittal section through a quail cerebellum to illustrate how cerebellar folding was measured. The green line (light grey adjacent to the darkly stained Purkinje cell layer in the print version) indicates the Purkinje cell layer whereas the black line is the outer contour if the cerebellum was an idealized sphere. The ratio between these 2 lengths provides the cerebellar foliation index [Iwaniuk et al., 2006]. Scale bar $=1 \mathrm{~mm}$.

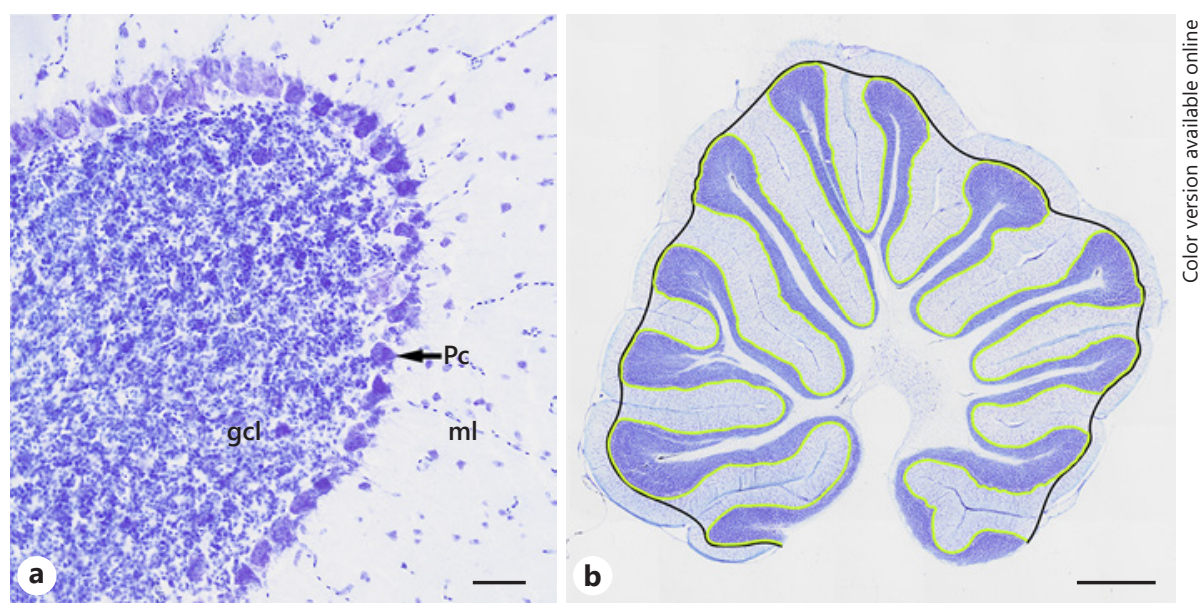

weighed, and their brains extracted. The cerebellum was dissected by cutting through the cerebellar peduncles. It was fixed in $4 \%$ paraformaldehyde for 2 weeks, cryoprotected in a 30\% sucrose phosphate buffered saline (PBS) solution and then stored in antifreeze at $-20^{\circ} \mathrm{C}$ until it was processed. All procedures complied with all relevant ethical regulations and were conducted under licenses provided by the Veterinary Office of the Canton of Zurich, Switzerland (permits 195/2010, 14/2014, 156).

\section{Cerebellum Histology}

After removal from the antifreeze, the cerebella were placed in $20 \%$ sucrose PBS for at least $24 \mathrm{~h}$ at room temperature and then transferred to $30 \%$ sucrose PBS solution until they had sunk. The sucrose PBS washes were needed to ensure that the antifreeze was removed prior to embedding in gelatin. The cerebella were then embedded in gelatin and sectioned sagittally on a freezing stage microtome at a thickness of $40 \mu \mathrm{m}$. All sections were collected and stored in PBS until mounting. Every second section was then mounted onto gelatinized microscope slides, stained for Nissl substance using thionin and coverslipped with Permount.

\section{Quantitative Measurements of the Cerebellum}

We used unbiased stereology [West, 2012] to quantify the volume of the cerebellum, its constituent layers and the size and number of Purkinje cells. All measurements were done blind to sex and selection line. Volumes of the entire cerebellum as well as the individual layers, the molecular, granule and white matter layers, were measured using the Cavalieri method [West, 2012] as implemented in Stereo Investigator (version 11.07, MBF Bioscience, Williston, VT USA). The molecular and granule cell layers are readily distinguishable from one another, and the intermediary Purkinje cell layer is identified based on cell size and density (Fig. 1a). We did not measure the volume of the Purkinje cell layer as it is only a single cell layer thick, and gaps between cells make it difficult to measure its volume effectively. Our measurement of the inner, white matter layer includes the cerebellar nuclei because it was not possible to reliably estimate their volumes. This is due to the highly irregular distribution of neurons within the cerebellar nuclei when viewed in the sagittal plane. For all 3 layers and the total cerebellar volume, the grid size was set to $358 \times 358 \mu \mathrm{m}$ and
Table 1. Pairwise correlations among cerebellar measures and body mass ( $n=43$ individuals)

\begin{tabular}{lrrrrrrr}
\hline & CBV & MLV & GLV & WMV & PCN & PCS & CFI \\
\hline MLV & $\mathbf{0 . 9 6 7}$ & & & & & & \\
GLV & $\mathbf{0 . 9 1 8}$ & $\mathbf{0 . 8 2 5}$ & & & & & \\
WMV & $\mathbf{0 . 7 4 6}$ & $\mathbf{0 . 6 2 9}$ & $\mathbf{0 . 6 1 9}$ & & & & \\
PCN & $\mathbf{0 . 3 6 4}$ & $\mathbf{0 . 3 8 9}$ & 0.279 & 0.265 & & & \\
PCS & -0.187 & -0.209 & -0.071 & -0.251 & -0.015 & & \\
CFI & -0.212 & -0.154 & -0.203 & -0.273 & -0.024 & 0.058 & \\
BM & -0.098 & -0.106 & -0.087 & -0.009 & 0.089 & -0.038 & 0.060
\end{tabular}

All variables were standardized before analysis. Pearson correlation coefficients are shown, with significant values highlighted in bold. CBV, total cerebellar volume; MLV, molecular layer volume; GLV, granule layer volume; WMV, white matter volume; PCN, number of Purkinje cells; PCS, Purkinje cell size; CFI, cerebellar foliation index; BM, body mass.

every 6 th mounted section (i.e., every 12 th section) was sampled through the medio-lateral extent of the cerebellum. Coefficients of error [West, 2012] ranged between 0.003 and 0.017 for our volumetric measurements.

The optical fractionator [West, 2012] was used to estimate the total number of Purkinje cells, also using StereoInvestigator. We set the grid size at $358 \times 358 \mu \mathrm{m}$ and the counting frame at $80 \times 80$ $\mu \mathrm{m}$. Section thickness was measured at each sampling site to account for variation in shrinkage within and across specimens [Schmitz and Hof, 2005]. Purkinje cells were identified as large cells with a rounded, teardrop shape within the Purkinje cell layer (Fig. 1a). Other neuron types in the cerebellar cortex are found in the outer molecular layer or inner granule cell layer, lack a teardrop shape to their cell bodies and are significantly smaller than Purkinje cells. Coefficients of error ranged between 0.03 and 0.05 for Purkinje cell counts.

Finally, Purkinje cell size was estimated using the nucleator probe [West, 2012] and the same settings for grid and frame sizes
Selection for Reproductive Investment and Cerebellar Neuron Size and Foliation
Brain Behav Evol 2020;95:69-77

DOI: $10.1159 / 000509068$ 

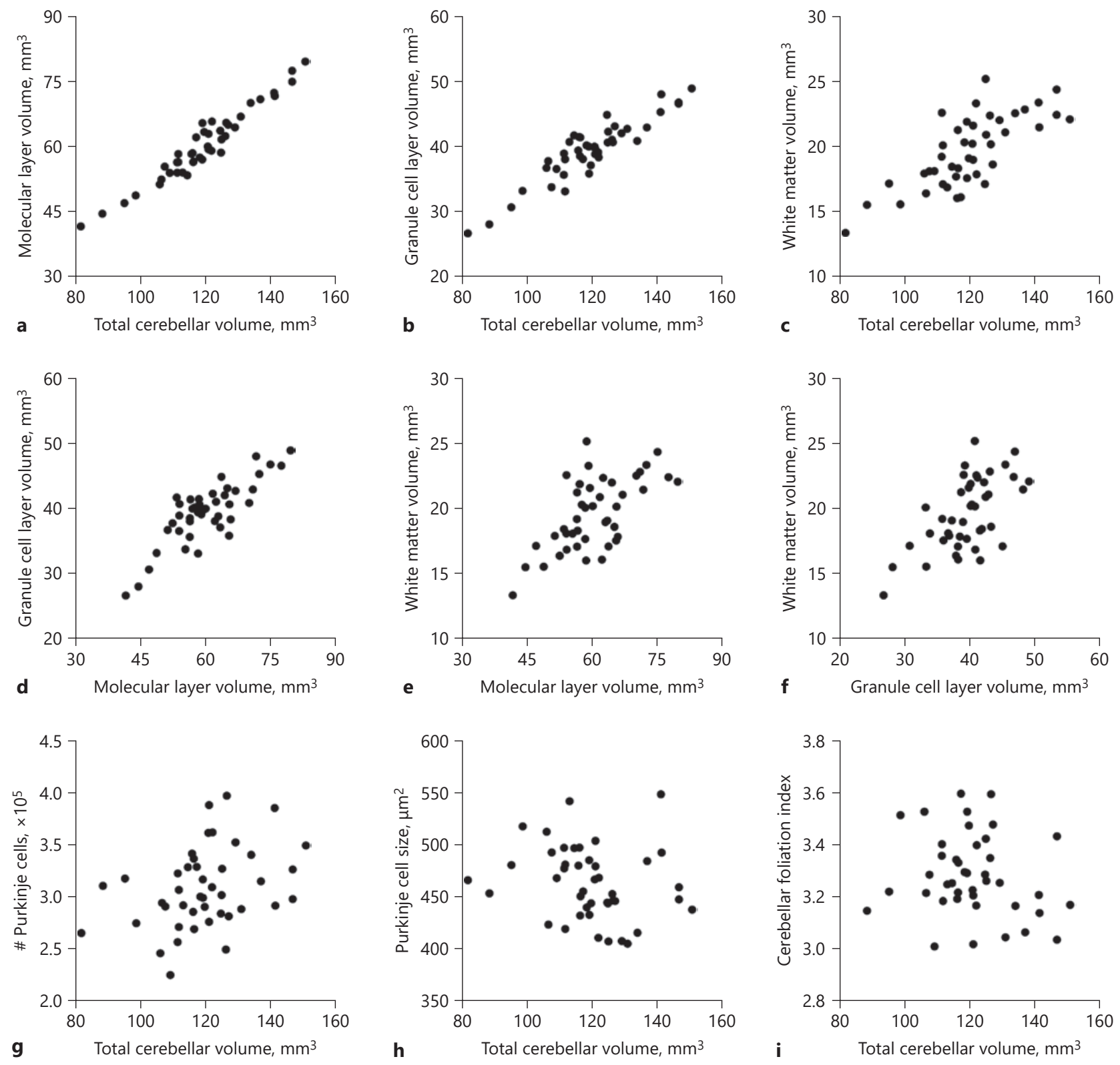

Fig. 2. Scatterplots depicting allometric relationships among volumes, Purkinje cell numbers, Purkinje cell sizes and cerebellar foliation across all of the quail examined. The scatterplots are as follows: molecular layer volume against total cerebellar volume (a); granule cell layer volume against total cerebellar volume (b); white matter volume against total cerebellar volume (c); granule cell layer volume against molecular layer volume (d); white matter volume against molecular layer volume (e); white matter volume against granule cell layer volume (f); number of Purkinje cells against total cerebellar volume (g); Purkinje cell soma size against total cerebellar volume $(\mathbf{h})$; cerebellar foliation index against total cerebellar volume (i). All of the volumes were significantly correlated with one another, and Purkinje cell numbers were significantly correlated with total cerebellar volume, but neither Purkinje cell sizes nor cerebellar foliation index was significantly correlated with total cerebellar volume (see Table 1). 
as the optical fractionator. We used the optical fractionator workflow to ensure that our sampling of Purkinje cells was randomized and systematic. The rays of the nucleator (rays $=4$ ) were placed on the centre of intact Purkinje cells, again defined as large cells with a teardrop shape and clearly visible nucleus. 30-50 Purkinje cells were measured for each subject for a total of 1,537 cells across all subjects. Coefficients of error were all $\leq 0.01$ with an average coefficient of variation of 0.211 across all subjects.

\section{Cerebellar Foliation}

Following Iwaniuk et al. [2006], we measured the degree of cerebellar foliation by tracing the outline of the Purkinje cell layer of midsagittal sections as well as an idealized envelope that only follows the outermost aspects of the cerebellar folia along the Purkinje cell layer (Fig. 1b). The ratio between these 2 linear measurements yields the degree of folding, termed the cerebellar foliation index (CFI), which is similar to the gyrification index used in studies of mammalian isocortex [Pillay and Manger, 2007].

\section{Statistical Analysis}

All analyses were performed in the $R$ statistical framework version 3.3.3 (R Development Core Team, 2015). First, we calculated pairwise Pearson correlation coefficients among our cerebellar measurements. We then used linear models to test for differences in cerebellar morphology between selection lines and sexes. Sex, selection line, their interaction and line replicate were included as fixed effects. The interaction term was removed from the final models if it was non-significant.

\section{Results}

\section{Correlations among Cerebellar Measures}

We observed strong positive correlations among total cerebellar volume, molecular layer volume, granule layer volume and white matter volume (Table 1; Fig. 2a-f). Furthermore, the number of Purkinje cells was significantly positively correlated with total cerebellar volume and molecular layer volume (Table 1; Fig. 2g). No other cerebellar measures were significantly correlated (Table 1; Fig. 2h, i), and none of the cerebellar measures was significantly correlated with body mass (Table 1).

\section{Differences in Cerebellar Measures between Selection \\ Line and Sexes}

We observed a pronounced difference in the size of Purkinje cells between the divergent selection lines (Table 2), with birds selected for high reproductive investment having significantly smaller Purkinje cells (Fig. 3a). This difference in Purkinje cell size between the divergent lines was similar in both independent line replicates (Line replicate 1: Cohen's $d=0.80$; Line replicate 2: Cohen's $d=$ $0.94)$. The line difference remained significant when including the number of Purkinje cells as a covariate in the
Table 2. Differences in cerebellar morphology between male and female birds selected for divergent reproductive investment

\begin{tabular}{|c|c|c|c|c|}
\hline & Estimate & $t$ & $\mathrm{df}$ & $p$ value \\
\hline \multicolumn{5}{|l|}{ Cerebellum volume } \\
\hline Selection line (L) & -7.427 & -1.748 & 1,39 & 0.088 \\
\hline $\operatorname{Sex}(M)$ & 7.821 & 1.853 & 1,39 & 0.072 \\
\hline Line replicate (2) & 6.882 & 1.638 & 1,39 & 0.109 \\
\hline Selection line $\times$ sex & -1.041 & -0.121 & 1,38 & 0.905 \\
\hline \multicolumn{5}{|l|}{ Molecular layer volume } \\
\hline Selection line (L) & -3.453 & -1.392 & 1,39 & 0.172 \\
\hline $\operatorname{Sex}(M)$ & 4.637 & 1.882 & 1,39 & 0.067 \\
\hline Line replicate (2) & 3.624 & 1.478 & 1,39 & 0.147 \\
\hline Selection line $\times$ sex & -1.189 & -0.236 & 1,38 & 0.814 \\
\hline \multicolumn{5}{|l|}{ Granule layer volume } \\
\hline Selection line (L) & -2.814 & -2.012 & 1,39 & 0.051 \\
\hline $\operatorname{Sex}(M)$ & 2.207 & 1.588 & 1,39 & 0.120 \\
\hline Line replicate (2) & 2.135 & 1.544 & 1,39 & 0.131 \\
\hline Selection line $\times$ sex & 1.653 & 0.585 & 1,38 & 0.562 \\
\hline \multicolumn{5}{|l|}{ White matter volume } \\
\hline Selection line (L) & -1.381 & -1.637 & 1,39 & 0.110 \\
\hline $\operatorname{Sex}(M)$ & 0.698 & 0.832 & 1,39 & 0.410 \\
\hline Line replicate (2) & 0.829 & 0.993 & 1,39 & 0.327 \\
\hline Selection line $\times$ sex & -1.274 & -0.749 & 1,38 & 0.458 \\
\hline \multicolumn{5}{|l|}{ Purkinje cell number } \\
\hline Selection line (L) & 8,258 & 0.670 & 1,39 & 0.507 \\
\hline $\operatorname{Sex}(M)$ & -1143 & -0.093 & 1,39 & 0.926 \\
\hline Line replicate (2) & -4142 & -0.340 & 1,39 & 0.736 \\
\hline Selection line $\times$ sex & 1,698 & 0.068 & 1,38 & 0.946 \\
\hline \multicolumn{5}{|l|}{ Purkinje cell size } \\
\hline Selection line $(\mathrm{L})$ & 28.902 & 2.809 & 1,39 & 0.008 \\
\hline $\operatorname{Sex}(M)$ & -6.336 & -0.620 & 1,39 & 0.539 \\
\hline Line replicate (2) & -5.202 & -0.511 & 1,39 & 0.612 \\
\hline Selection line $\times$ sex & 6.179 & 0.296 & 1,38 & 0.769 \\
\hline \multicolumn{5}{|l|}{ Cerebellar foliation index } \\
\hline Selection line (L) & -0.105 & -1.521 & 1,36 & 0.137 \\
\hline $\operatorname{Sex}(M)$ & -0.075 & -1.187 & 1,36 & 0.243 \\
\hline Line replicate (2) & 0.030 & 0.620 & 1,36 & 0.539 \\
\hline Selection line $\times$ sex & 0.232 & 2.424 & 1,36 & 0.021 \\
\hline
\end{tabular}

Significant $p$ values are highlighted in bold.

analysis (selection line: $t_{1,38}=2.807, p=0.008$, Purkinje cell number: $\left.t_{1,38}=-0.410, p=0.684\right)$, highlighting that there was no indication of a tradeoff between number and size of Purkinje cells. Furthermore, the line effect was similar in males and females (Table 2).

In addition, we observed a significant interaction effect between selection line and sex on CFI (Table 2; Fig. 3b). Males had a significantly higher CFI than females in the lines selected for low reproductive investment 
Fig. 3. a Mean $( \pm S E)$ Purkinje cell size $\left(\mathrm{mm}^{2}\right)$ of male and female Japanese quail artificially selected for divergent reproductive investment. b Mean $( \pm \mathrm{SE})$ cerebellar foliation index (CFI) of male and female Japanese quail artificially selected for divergent reproductive investment. In both plots: high, high maternal investment selection lines; low, low maternal investment selection lines.

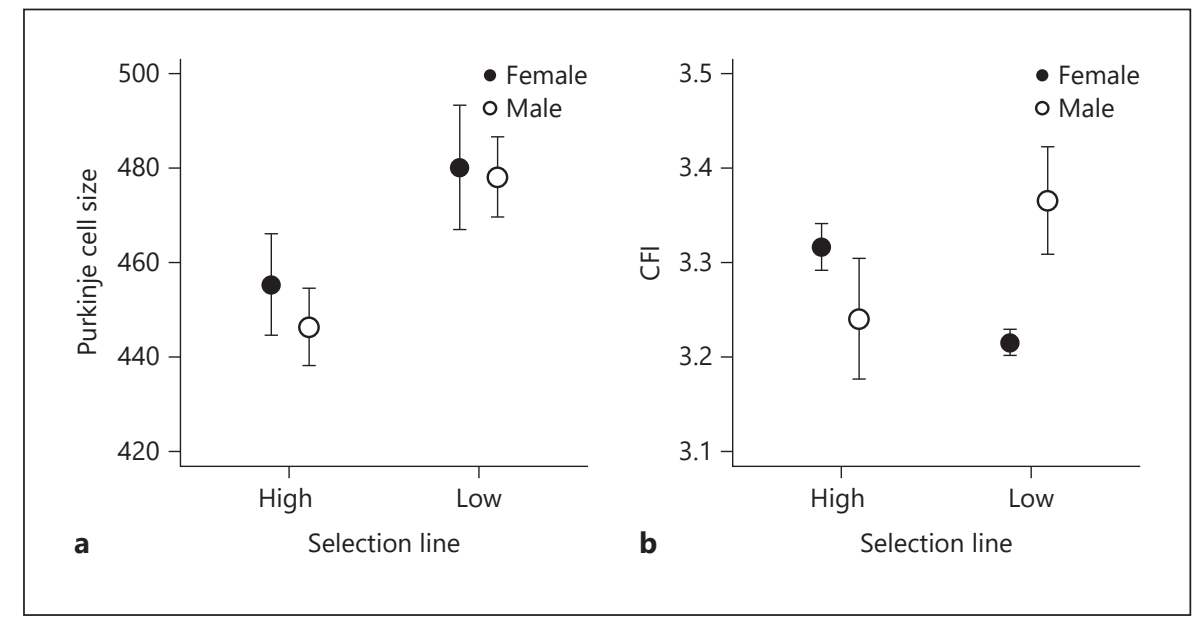

(contrast: $p=0.037$ ), whereas no significant sex difference in CFI was observed in the lines selected for high reproductive investment (contrast: $p=0.243$ ). Furthermore, males from the low reproductive investment lines had higher CFI values than males from high reproductive investment (contrast: $p=0.062$ ), whereas no difference was observed in females from the divergent lines (contrast: $p=0.137$; Fig. 3b). No significant difference between selection lines and/or sexes was observed for any of the other cerebellar measures (Table 2).

\section{Discussion}

Across selection lines and sexes, our volumetric data yielded strong correlations among the layer volumes, and between the layer volumes and total cerebellar volume. Thus, larger cerebella are due to coordinated increases across the layers in quail. Given the highly conserved circuitry of the cerebellum [Yopak et al., 2016], these scaling relationships are unsurprising. In contrast, the number of Purkinje cells varied significantly with total cerebellar volume and molecular layer volume, but not any of the other measurements. Further, Purkinje cell size and CFI did not vary significantly with any of the measurements. Thus, a larger cerebellum had coordinated changes across cerebellar layers and more Purkinje cells, but not necessarily larger Purkinje cells or a more folded morphology. This suggests that allometry cannot explain all of the inter-individual variation in our quantitative measurements of the cerebellum and that factors other than cerebellum size are related to Purkinje cell size and CFI. Intra- or interspecific allometry of Purkinje cell numbers or sizes has yet to be examined systematically, so it is difficult to interpret these findings other than to conclude that allometric constraints do not affect all of our measurements equally. The lack of an allometric effect on Purkinje cell size and CFI also suggests that our selection line-specific effects on these two measurements are not simply a product of cerebellum size.

Although cerebellum size varied across the individuals sampled, in contrast to Ebneter et al. [2016], we did not detect a significant selection line effect on cerebellum size. This may be due to a smaller sample size in the current study (total $n=43$ ) compared with that of Ebneter et al. [2016] (total $n=277$ ). Despite this smaller sample size, we detected a significant effect of selection line on average Purkinje cell size; high-investment quail of both sexes had significantly smaller cells than low-investment quail. The extent to which Purkinje cell soma size reflects the size of the dendritic tree is unknown, but a change in soma size could reflect physiological activity. In a songbird premotor nucleus, the robust nucleus of the arcopallium, neuron soma sizes increase during the breeding season [Smith et al., 1997], and this is associated with enhanced spontaneous firing activity and an increase in singing behaviour [Park et al., 2005]. Although this is a highly specific example from outside of the cerebellum, it is possible that a similar relationship between Purkinje cell activity and size applies here. That is, the smaller Purkinje cells of the high-investment quail are less active. In mammals, motor learning and coordination are dependent on Purkinje cell activity [Thach, 1998; Nguyen-Vu et al., 2013] and motor learning induces an increase in the number of Purkinje cell synapses [Black et al., 1990; Kleim et al., 1998], which would expand the size of the dendritic tree. If the same phenomena apply here, then we predict that low-invest- 
ment line quail would perform better than high-investment quail in tests of motor function [Metz and Whishaw, 2002; Cnotka et al., 2007; Spence et al., 2009] and that the dendritic tree of the Purkinje cells will be larger in the low-investment than the high-investment strain.

The degree of cerebellar folding, as measured with CFI, also differed between the selection lines, but this marginal effect was only evident in males. It should be noted that the degree of cerebellar foliation was more variable among males than females (Fig. 3b), even though there was comparable variance between the sexes in Purkinje cell sizes (Fig. 3a) and other measurements. This sex difference in CFI variability within both selection lines is unexpected and the underlying cause unknown at this time. Why we found a significant difference between the 2 selection lines in males is also unexpected, particularly when one considers that maternal egg investment was selected to create the divergent lines [Pick et al., 2016a]. However, previous work in this system demonstrated correlated responses of selection for female reproductive investment on male reproductive performance, as well as changes in testes morphology in males from the divergent lines [Pick et al., 2017]. Differences in Purkinje cell size and cerebellar folding in males could thus be a direct consequence of different reproductive strategies (i.e., plastic resource allocation) and/or reflect (sex-specific) genetic correlations between reproductive performance and cerebellar morphology.

Cerebellar foliation arises from a combination of specific signalling pathways, Bergmann glia acting as anchoring points, and the physical structure of the 3-layered cerebellar cortex [Sudarov and Joyner, 2007; Lejeune et al., 2016; Leung and Li, 2018]. Perturbations to the signalling mechanisms often results in either a misfolded or less folded cerebellar cortex [Leung and Li, 2018] and aberrant cerebellar foliation is a feature of several neurological disorders [Demaerel, 2002]. Across birds, species with more folded cerebella are more likely to use tools [Iwaniuk et al., 2009] and build more complex nests [Hall et al., 2013], suggesting that cerebellar foliation is also associated with sensorimotor integration and/or fine motor skills. Similarly, mutant mice with less folded cerebella exhibit a range of motor coordination deficits [Lalonde and Strazielle, 2001] and inbred mouse lines with subtle changes in cerebellar foliation vary in motor coordination [Le Roy-Duflos, 2001]. Based on differences in CFI, we would therefore predict that high-investment line males might be less coordinated than low-investment line males, similar to what we predict based on our Purkinje cell size data. However, this prediction should be tem-

Selection for Reproductive Investment and Cerebellar Neuron Size and Foliation pered by a relatively weak effect and the large variation in CFI among males (Fig. 3b).

One potential mechanism related to development that could be partially responsible for the differences observed between strains is neurogenesis. The external granular layer is the source of granule cells in the avian cerebellum and proliferation of these cells extends well past hatching [Stamatakis et al., 2004]. Differences in reproductive investment could alter the length of this period of proliferation and increase the number of granule cells. Although we did not detect significant differences in granule cell layer or total cerebellar volume between the 2 strains, we were unable to count granule cells. It is therefore possible that the packing density of the granule cells is greater in the low-investment quail, which could then result in higher CFI (at least in males) and larger Purkinje cells due to a higher density of parallel fibres. This is highly speculative, but future studies of neurogenesis could provide some valuable insights into the mechanisms that underlie differences in cerebellar anatomy between these strains and strains within other species [e.g., Henriksen et al., 2016].

Regardless of the possible functional consequences of the differences between the selection lines, it is clear that selection for differential maternal investment has caused specific cellular and morphological changes in the cerebellum. Further, these changes are not manifested at the level of volumetric data or Purkinje cell numbers. From this we conclude that the addition or subtraction of neurons is not the only way that selection can act on the anatomical structure of a brain region. A similar conclusion was reached by Herculano-Houzel et al. [2015] in their analysis of neuron and non-neuronal cell numbers within a mouse strain. In contrast to interspecific datasets where the majority of brain region differences among species reflect neuron numbers [Herculano-Houzel et al., 2015], differences in cerebellum size among individual mice within a strain were not significantly correlated with number of neurons or neuronal density [HerculanoHouzel et al., 2015]. In fact, the strongest predictor of individual cerebellum size was number of non-neuronal cells [Spearman $\rho=0.57$, Herculano-Houzel et al., 2015]. Our data also reveals the complexity of neuron size, neuron number and brain region volume inter-relationships in that Purkinje cell numbers were correlated with cerebellum size across all quail, but Purkinje cell size and not numbers varied between strains. Thus, in accordance with the conclusion of Herculano-Houzel et al. [2015], selection acted on neuron size rather than neuron numbers. Whether this differs from interspecific scaling or not 
remains to be determined, but based on our results, diversity in cerebellar size and shape is likely to be a product of increasing both neuron numbers and neuron sizes [Herculano-Houzel et al., 2015].

\section{Acknowledgements}

We wish to thank Christina Ebneter for her assistance in dissecting the quail brains and an anonymous reviewer for comments. Funding for this study was provided by a Natural Sciences and Engineering Research Council of Canada (NSERC) USRA scholarship to R.E.A., NSERC Discovery, Canada Foundation for Innovation, and Canada Research Chairs Program grants to A.N.I. and Swiss National Science Foundation grants (PP00P3_128386, PP00P3_157455) to B.T.

\section{Statement of Ethics}

All procedures complied with all relevant ethical regulations and were conducted under licenses provided by the Veterinary Office of the Canton of Zurich, Switzerland (permits 195/2010, $14 / 2014,156)$.

\section{Conflict of Interest Statement}

The authors have no conflicts of interest to declare.

\section{Funding Sources}

Funding for the quail selection experiment was provided by the Swiss National Science Foundation to B.T. All histology and analyses were supported by grants to A.N.I. from the Natural Sciences and Engineering Research Council of Canada, Canada Research Chairs Program, and Canada Foundation for Innovation.

\section{Author Contributions}

All authors had full access to all the data in the study and take responsibility for the integrity of the data and the accuracy of the data analysis. Study concept and design: B.T. and A.N.I. Acquisition of data: R.E.A., F.C., B.T., and A.N.I. Analysis and interpretation of data: B.T. A.N.I. Drafting of the manuscript: R.E.A., B.T., and A.N.I. Critical revision of the manuscript for important intellectual content: F.C., B.T., and A.N.I. Obtained funding: B.T. and A.N.I. Administrative, technical, and material support: B.T. and A.N.I. Study supervision: B.T. and A.N.I.

\section{References}

Airey DC, Lu L, Shou S, Williams RW. Genetic sources of individual differences in the cerebellum. Cerebellum. 2002 Dec;1(4):233-40.

Bernard JA, Leopold DR, Calhoun VD, Mittal VA. Regional cerebellar volume and cognitive function from adolescence to late middle age. Hum Brain Mapp. 2015 Mar;36(3):1102-20.

Berquin PC, Giedd JN, Jacobsen LK, Hamburger SD, Krain AL, Rapoport JL, et al. Cerebellum in attention-deficit hyperactivity disorder: a morphometric MRI study. Neurology. 1998 Apr;50(4):1087-93.

Black JE, Isaacs KR, Anderson BJ, Alcantara AA, Greenough WT. Learning causes synaptogenesis, whereas motor activity causes angiogenesis, in cerebellar cortex of adult rats. Proc Natl Acad Sci USA. 1990 Jul;87(14):5568-72.

Cnotka J, Frahm HD, Mpotsaris A, Rehkämper G. Motor incoordination, intracranial fat bodies, and breeding strategy in Crested ducks (Anas platyrhynchos f.d.). Poult Sci. 2007 Sep;86(9): $1850-5$.

Demaerel P. Abnormalities of cerebellar foliation and fissuration: classification, neurogenetics and clinicoradiological correlations. Neuroradiology. 2002 Aug;44(8):639-46.

Ebneter C, Pick JL, Tschirren B. A trade-off between reproductive investment and maternal cerebellum size in a precocial bird. Biol Lett. 2016 Dec;12(12):20160659.

Fan L, Tang Y, Sun B, Gong G, Chen ZJ, Lin X, et al. Sexual dimorphism and asymmetry in human cerebellum: an MRI-based morphometric study. Brain Res. 2010 Sep;1353:60-73.
Hall ZJ, Street SE, Healy SD. The evolution of cerebellum structure correlates with nest complexity. Biol Lett. 2013 Dec;9(6):20130687.

Hayashi T, Onozato T, Wanajo I, Hayashi M, Takeda H, Fujimori Y. Longitudinal analysis of motor symptoms and histopathology in woozy mice, a model of cerebellar ataxia. Neuroreport. 2017 Sep;28(13):779-87.

Henriksen R, Johnsson M, Andersson L, Jensen P, Wright $\mathrm{D}$. The domesticated brain: genetics of brain mass and brain structure in an avian species. Sci Rep. 2016 Sep;6(1):34031.

Herculano-Houzel S, Catania K, Manger PR, Kaas JH. Mammalian brains are made of these: a dataset of the numbers and densities of neuronal and nonneuronal cells in the brain of Glires, Primates, Scandentia, Eulipotyphlans, Afrotherians and Artiodactyls, and their relationship with body mass. Brain Behav Evol. 2015;86(3-4):145-63.

Herculano-Houzel S, Messeder DJ, Fonseca-Azevedo K, Pantoja NA. When larger brains do not have more neurons: increased numbers of cells are compensated by decreased average cell size across mouse individuals. Front Neuroanat. 2015 Jun;9:64.

Iwaniuk AN, Hurd PL, Wylie DR. Comparative morphology of the avian cerebellum: I. Degree of foliation. Brain Behav Evol. 2006; 68(1):45-62.

Iwaniuk AN, Hurd PL, Wylie DR. Comparative morphology of the avian cerebellum: II. Size of folia. Brain Behav Evol. 2007;69(3):196219.
Iwaniuk AN, Lefebvre L, Wylie DR. The comparative approach and brain-behaviour relationships: a tool for understanding tool use. Can J Exp Psychol. 2009 Jun;63(2):150-9.

Jerison HJ. The evolution of brain and intelligence. New York: Academic Press; 1973.

Kihslinger RL, Nevitt GA. Early rearing environment impacts cerebellar growth in juvenile salmon. J Exp Biol. 2006 Feb;209(Pt 3):504-9.

Kleim JA, Swain RA, Armstrong KA, Napper RM Jones TA, Greenough WT. Selective synaptic plasticity within the cerebellar cortex following complex motor skill learning. Neurobiol Learn Mem. 1998 May;69(3):274-89.

Lalonde R, Strazielle C. Motor performance and regional brain metabolism of spontaneous murine mutations with cerebellar atrophy. Behav Brain Res. 2001 Nov;125(1-2):103-8.

Larsell O. The Comparative Anatomy and Histology of the Cerebellum from Myxinoids through Birds. Minneapolis: University of Minnesota Press; 1967.

Larsell $\mathrm{O}$. The Comparative Anatomy and Histology of the Cerebellum from Monotremes through Apes. Minneapolis: University of Minnesota Press; 1970

Le Roy-Duflos I. Possible causal relationships between cerebellar patterns of foliation and hindlimb coordination in laboratory mice: a quantitative trait locus analysis. Behav Genet. 2001 Jan;31(1):29-37. 
Lejeune E, Javili A, Weickenmeier J, Kuhl E, Linder C. Tri-layer wrinkling as a mechanism for anchoring center initiation in the developing cerebellum. Soft Matter. 2016 Jul;12(25): 5613-20.

Leung AW, Li JY. The molecular pathway regulating Bergmann glia and folia generation in the cerebellum. Cerebellum. 2018 Feb;17(1):428.

Lisney TJ, Yopak KE, Montgomery JC, Collin SP. Variation in brain organization and cerebellar foliation in chondrichthyans: batoids. Brain Behav Evol. 2008;72(4):262-82.

Metz GA, Whishaw IQ. Cortical and subcortical lesions impair skilled walking in the ladder rung walking test: a new task to evaluate foreand hindlimb stepping, placing, and co-ordination. J Neurosci Methods. 2002 Apr;115(2): 169-79.

Nguyen-Vu TD, Kimpo RR, Rinaldi JM, Kohli A, Zeng H, Deisseroth K, et al. Cerebellar Purkinje cell activity drives motor learning. Nat Neurosci. 2013 Dec;16(12):1734-6.

Olkowicz S, Kocourek M, Lučan RK, Porteš M, Fitch WT, Herculano-Houzel S, et al. Birds have primate-like numbers of neurons in the forebrain. Proc Natl Acad Sci USA. 2016 Jun; 113(26):7255-60.

Park KH, Meitzen J, Moore IT, Brenowitz EA, Perkel DJ. Seasonal-like plasticity of spontaneous firing rate in a songbird pre-motor nucleus. J Neurobiol. 2005 Aug;64(2):181-91.

Pick JL, Ebneter C, Hutter P, Tschirren B. Disentangling genetic and prenatal maternal effects on offspring size and survival. Am Nat. 2016c Dec;188(6):628-39.
Pick JL, Hutter P, Ebneter C, Ziegler AK, Giordano $M$, Tschirren B. Artificial selection reveals the energetic expense of producing larger eggs. Front Zool. 2016b Aug;13(1):38.

Pick JL, Hutter P, Tschirren B. In search of genetic constraints limiting the evolution of egg size: direct and correlated responses to artificial selection on a prenatal maternal effector. Heredity. 2016a Jun;116(6):542-9.

Pick JL, Hutter P, Tschirren B. Divergent artificial selection for female reproductive investment has a sexually concordant effect on male reproductive success. Evol Lett. 2017 Aug;1(4): 222-8.

Pillay P, Manger PR. Order-specific quantitative patterns of cortical gyrification. Eur J Neurosci. 2007 May;25(9):2705-12.

Schmitz C, Hof PR. Design-based stereology in neuroscience. Neuroscience. 2005;130(4): 813-31.

Smaers JB, Turner AH, Gómez-Robles A, Sherwood CC. A cerebellar substrate for cognition evolved multiple times independently in mammals. eLife. 2018 May;7:e35696.

Smith GT, Brenowitz EA, Beecher MD, Wingfield JC. Seasonal changes in testosterone, neural attributes of song control nuclei, and song structure in wild songbirds. J Neurosci. 1997 Aug; 17(15):6001-10.

Spence RD, Zhen Y, White S, Schlinger BA, Day LB. Recovery of motor and cognitive function after cerebellar lesions in a songbird: role of estrogens. Eur J Neurosci. 2009 Mar;29(6): 1225-34.
Stamatakis A, Barbas H, Dermon CR. Late granule cell genesis in quail cerebellum. J Comp Neurol. 2004 Jun;474(2):173-89.

Striedter GF. Principles of brain evolution. Sunderland: Sinauer Associates; 2005.

Sudarov A, Joyner AL. Cerebellum morphogenesis: the foliation pattern is orchestrated by multi-cellular anchoring centers. Neural Dev. 2007 Dec;2(1):26.

Thach WT. A role for the cerebellum in learning movement coordination. Neurobiol Learn Mem. 1998 Jul-Sep;70(1-2):177-88.

Vogel MW, Sunter K, Herrup K. Numerical matching between granule and Purkinje cells in lurcher chimeric mice: a hypothesis for the trophic rescue of granule cells from target-related cell death. J Neurosci. 1989 Oct;9(10): 3454-62.

Wang T, Morgan JI. The Purkinje cell degeneration (pcd) mouse: an unexpected molecular link between neuronal degeneration and regeneration. Brain Res. 2007 Apr;1140:26-40.

West MJ. Introduction to stereology. Cold Spring Harb Protoc. 2012;7:843-51.

Yopak KE, Lisney TJ, Collin SP, Montgomery JC. Variation in brain organization and cerebellar foliation in chondrichthyans: sharks and holocephalans. Brain Behav Evol. 2007;69(4): 280-300.

Yopak KE, Pakan J, Wylie D. The cerebellum of non-mammalian vertebrates. In: Kaas $\mathrm{JH}$, Striedter GF, editors. Evolution of Nervous Systems. 2nd ed. New York: Academic Press; 2017. p. 373-85. 